\title{
Performance of 45-year-old corroded prestressed concrete beams
}

1 Torill M. Pape BE (Hons), PhD Research Associate, University of Newcastle, Callaghan, New South Wales, Australia
2 Robert E. Melchers BE (Hons I), MEngSc, Dip Ed, PhD Professor of Civil Engineering, University of Newcastle, Callaghan, New South Wales, Australia

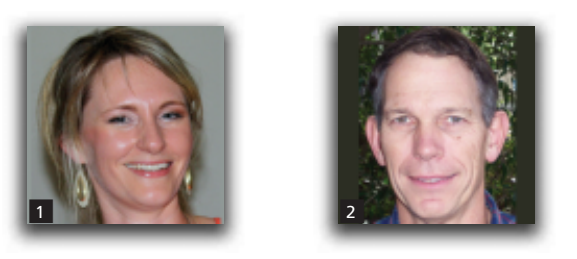

The design of prestressed concrete bridge beams usually assumes that the full capacity of the tendons can be achieved under ultimate load, based on the assumption of sufficient deformation capacity of the prestressing wires. Whether this is achieved also in older bridges is of increasing interest in remaining-life assessments since, especially in aggressive marine environments, corrosion of steel is known to cause loss of wire ductility. Results are reported herein of load tests to destruction for three full-sized and deteriorated prestressed concrete bridge beams recovered from a 45-year-old bridge exposed to an aggressive marine environment. The two beams with the greatest superficial deterioration showed progressive and premature failure of the prestressing wires. The beam with little superficial deterioration also showed progressive failure and failed to reach the ultimate load capacity based on current design theory and actual material properties. Possible reasons for the observed behaviour and the practical implications are discussed.

\section{Introduction}

For most nations, an essential part of the economy is the road transport system, and bridges are critical components within it. Bridge failure typically incurs direct and indirect costs far in excess of the cost of bridge repair or replacement. Many prestressed concrete bridges were constructed from the 1950s onward and the oldest of these are now nearing the end of their design lives (LeBeau and Wadia-Fascetti, 2010). The current structural adequacy and the likely remaining safe life of existing prestressed concrete bridges typically are estimated using periodic visual inspections coupled with a rating system (e.g. Cavell and Waldron, 2001). In some cases load testing may also be used. These results can be compared with structural analyses using known, measured and assumed loadings and material properties, considering the usual structural failure modes and, sometimes, also fatigue and corrosion. Much research attention is being given to improving the analysis techniques (Neves and Frangopol, 2008; Val and Chernin, 2008). However, relatively little attention is being given to the effect of deterioration on modes of failure and the modelling of the associated mechanisms and risks (Darmawan and Stewart, 2007; Ting and Nowak, 1991).

Conventional design and analysis of prestressed concrete beams assumes that the ultimate bending capacity can be estimated using internal bending equilibrium, with the force in the tendon at each cross-section being equally distributed between the wires making up the tendon. This is assumed to occur through the whole loading process, including to ultimate load (Abeles and Bardhan-Roy, 1981), and relies on the notion that sufficient deformation can occur in the individual wires between their reaching proof stress and ultimate stress. As a result, there should be a gradual rather than sudden or brittle failure of the tendon and thus of the overall prestressed concrete element. In this sense, there is no difference between reinforced concrete and prestressed concrete beam design in the estimation of the ultimate bending strength (Gilbert and Mickleborough, 1990). In the case of older bridges where corrosion of the steel has occurred, this assumption may not be appropriate. It is known that localised corrosion in particular tends to reduce the ductility of steel reinforcement (Cairns et al., 2005). This can be expected to occur also for prestressing wire. Only a small number of studies have investigated the effect of reinforcement or prestressing corrosion on bridge beam behaviour and these have focused predominantly on the effect on ultimate capacity; estimated using analytical or laboratory studies on hypothetical elements (Coronelli et al., 2009; Zeng et al., 2010) or actual prestressed bridges (Schupack, 1978; Woodward and Williams, 1988). There appears to have been no correlation of these results to previous experience. 
In the present study, results are reported of load tests on three prestressed concrete beams recovered from a 45-year-old bridge continuously exposed over its life to an aggressive, cool, marine environment. One of the beams was severely cracked and another moderately cracked, in both cases consistent with tendon corrosion (Schupack, 1978). The third beam was, superficially, in very good condition. When the beams were load tested in the laboratory, the load-response behaviour of all beams showed progressive failure of the prestressing wires. However, none of the beams reached the expected design capacity, including the beam superficially in very good condition. It is considered that these observations potentially have serious implications for the assessment of the remaining life of existing prestressed concrete bridges located in marine environments. The following sections describe, in turn, the bridge beams and their properties, the load tests that were performed and the experimental results obtained. This is followed by a discussion of the possible reasons for the observed results.

\section{Background}

The bridge beams considered herein were recovered during the demolition of the $457 \mathrm{~m}$ long Sorell Causeway Bridge during
2002, following increasing concern about its safety in the light of observations of corrosion of the prestressing tendons in the beams and of the reinforcement in the crossheads. The bridge, when completed in 1957, was the first prestressed, precast bridge of its kind in Australia (Coombs, 1957). It was located approximately $20 \mathrm{~km}$ from Hobart, south-east Tasmania, and spanned across the Pitt Water estuary, an aggressive marine environment open to strong winds. The bridge was composed of 34 simply supported $13 \mathrm{~m}$-long spans, each consisting of 14 precast, post-tensioned ' $\mathrm{T}$ ' beams connected together transversely by post-tensioning through five equally spaced diaphragms (Figures 1 and 2) (Pape and Melchers, 2011).

The beams were manufactured on site in steel moulds using local basalt and quartz sand. Inspection of the concrete after the beams were load tested (see below) showed that all were of solid construction with minimal voids. Records also reveal that calcium chloride was added as a setting accelerant for the concrete mix. The post-tensioning tendons were drawn through ducts formed parabolically using inflatable rubber tubes that were subsequently withdrawn, leaving the ducts unlined (Zollman et al., 1992). Table 1 shows the coordinates of the upper and lower ducts. Each

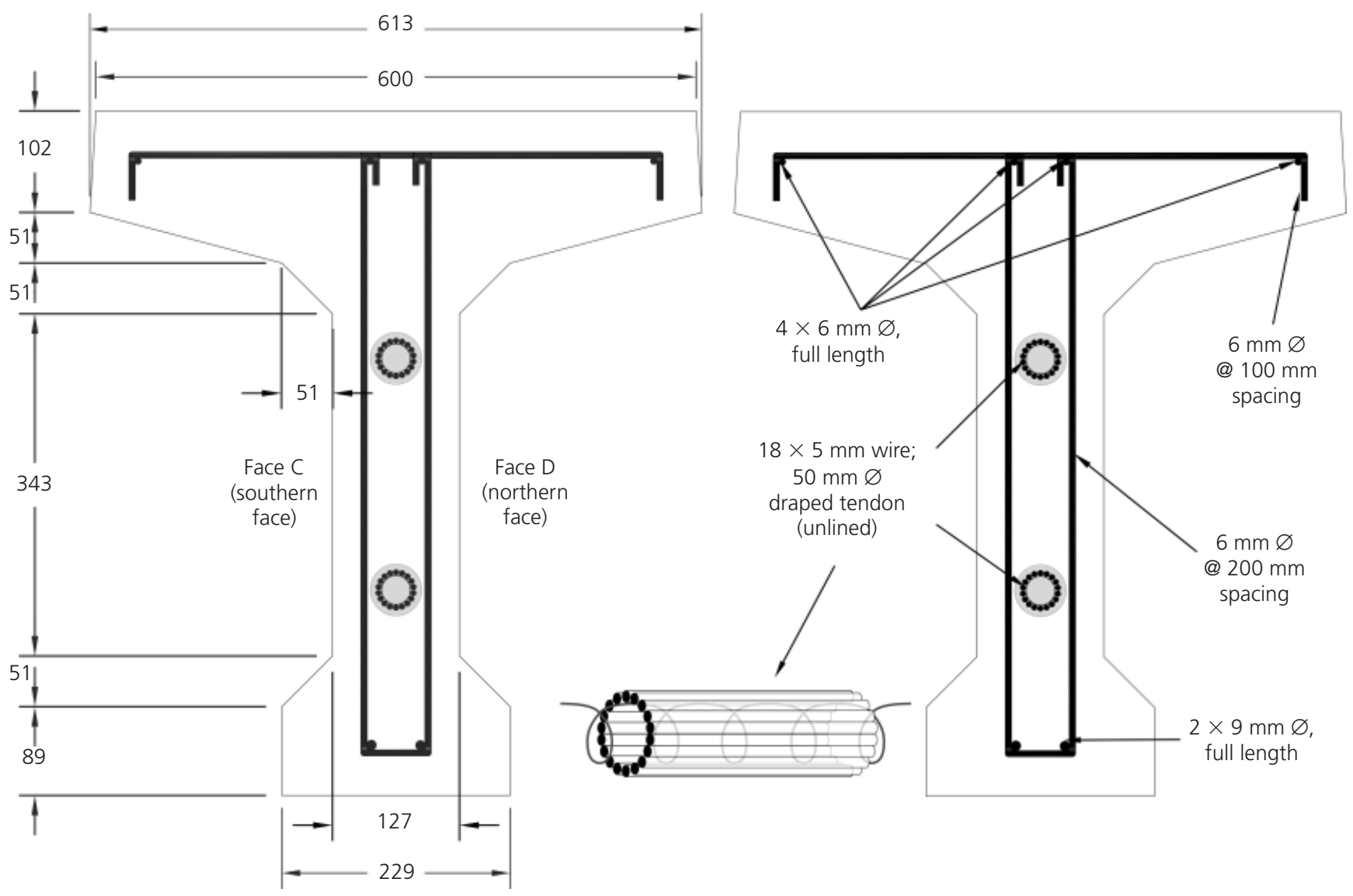

Figure 1. Cross-section of typical prestressed T-beam showing (left) dimensions in mm (converted from Imperial units) and (right) reinforcement and prestressing details 


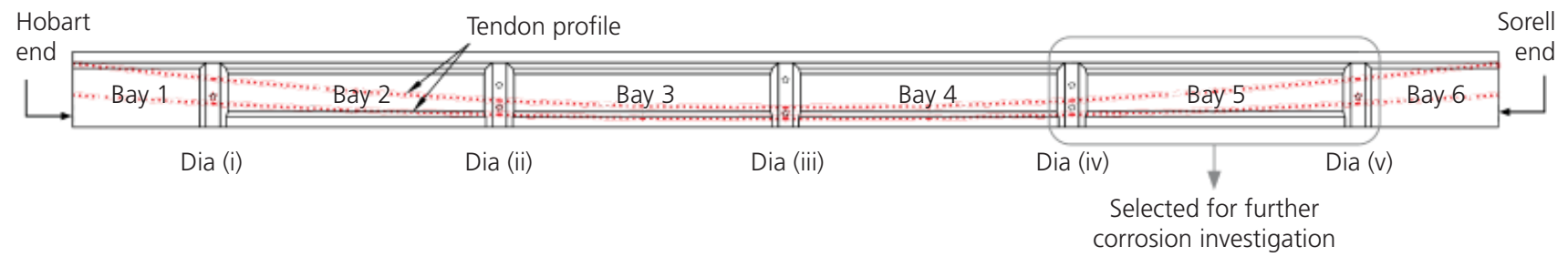

Figure 2. Elevation of typical prestressed T-beam showing bays 1-6 of the beam, its diaphragms (i)-(v) through which transverse prestressing was applied, and the longitudinal parabolic tendon profiles (note 'Dia' denotes diaphragm in all artwork)

\begin{tabular}{|c|c|c|c|c|c|c|c|}
\hline & End & $\begin{array}{c}\text { Diaphragm } \\
\text { (i) }\end{array}$ & $\begin{array}{c}\text { Diaphragm } \\
\text { (ii) }\end{array}$ & $\begin{array}{l}\text { Diaphragm } \\
\text { (iii) }\end{array}$ & $\begin{array}{l}\text { Diaphragm } \\
\text { (iv) }\end{array}$ & $\begin{array}{c}\text { Diaphragm } \\
\text { (v) }\end{array}$ & End \\
\hline Distance along beam & 0 & 1270 & 3861 & 6452 & 9042 & 11633 & 12903 \\
\hline Height to upper tendon (from base) & 578 & 438 & 241 & 178 & 241 & 438 & 578 \\
\hline Height to lower tendon (from base) & 272 & 216 & 114 & 76 & 114 & 216 & 272 \\
\hline
\end{tabular}

tendon consisted of $18 \times 5 \cdot 1 \mathrm{~mm}$ dia. cold-rolled, high-tensile wire. The wires were individually stressed (using the now superseded Freyssinet method) and the ducts subsequently pressure grouted with gypsum mortar. Unpublished project records and recent testing showed that calcium chloride was not added to the grout mix. Figure 1 shows that the beams contained only minimal conventional reinforcement.

\section{Beam test specimens}

During the demolition of the bridge, a number of beams were selected for investigation. The beams were selected on the basis of having superficially

(a) little or no cracking damage

(b) medium damage

(c) the most severe damage representative of all beams from the bridge.

Table 2 summarises the condition of the three beams (and refers to Figure 3). Crack and defect patterns for each beam before and after load testing are shown across one face in Figures 4(a), 5(a) and 6(a) and Figures 4(b), 5(b) and 6(b) respectively.

\section{Load testing of beams}

Each beam was load tested to destruction using the four-point system shown in Figure 7(a). The beams were supported at both ends on specially fabricated steel supports that closely replicated the original bearing plates. Each beam was loaded on the top using two $250 \mathrm{kN}$ hydraulic jacks suspended from an overhead steel frame bolted to the laboratory strong floor. The loads were applied at third points along the beam, inducing a constant moment across the central region of the beam. This approximated the bending moment distribution expected from a uniformly distributed load, in accordance with the loading system usually considered dominant for the design and analysis of bridge beams (Standards Australia, 2004).

The loading process was digitally controlled remotely for safety reasons as the deflections increased. The maximum loads expected to be applied to the beams were based on estimations of the specified concrete strength and prestressing steel strength (equivalent to $34 \mathrm{MPa}$ and $1670 \mathrm{MPa}$ respectively) and making an allowance of $25 \%$ losses due to shrinkage and creep. Thus, the maximum load anticipated under each hydraulic jack for a beam in sound condition and free of corrosion was $125 \mathrm{kN}$, with the beam failing in bending and in a ductile manner. Shear or a combination of shear and bending due to the application of loads were not considered to be a critical failure mechanism. For the tests, load increments of $25 \mathrm{kN}$ were used initially, but at high loads, as the beam neared failure and was yielding rapidly, load levels were difficult to sustain and very low increments were necessary.

Concrete strain measurements were recorded continuously throughout the test using $12 \times 10 \mathrm{~mm}$ potentiometers. These were fixed on both sides of diaphragm (iii) and down both faces of the beam at midspan, as shown in Figure 7(b). Similarly, midspan deflections were measured continuously by way of a computer using two $100 \mathrm{~mm}$ displacement potentiometers positioned under each side of diaphragm (iii). After the application of each load 


Beam Casting date Location in bridge Condition

number (in 1956)

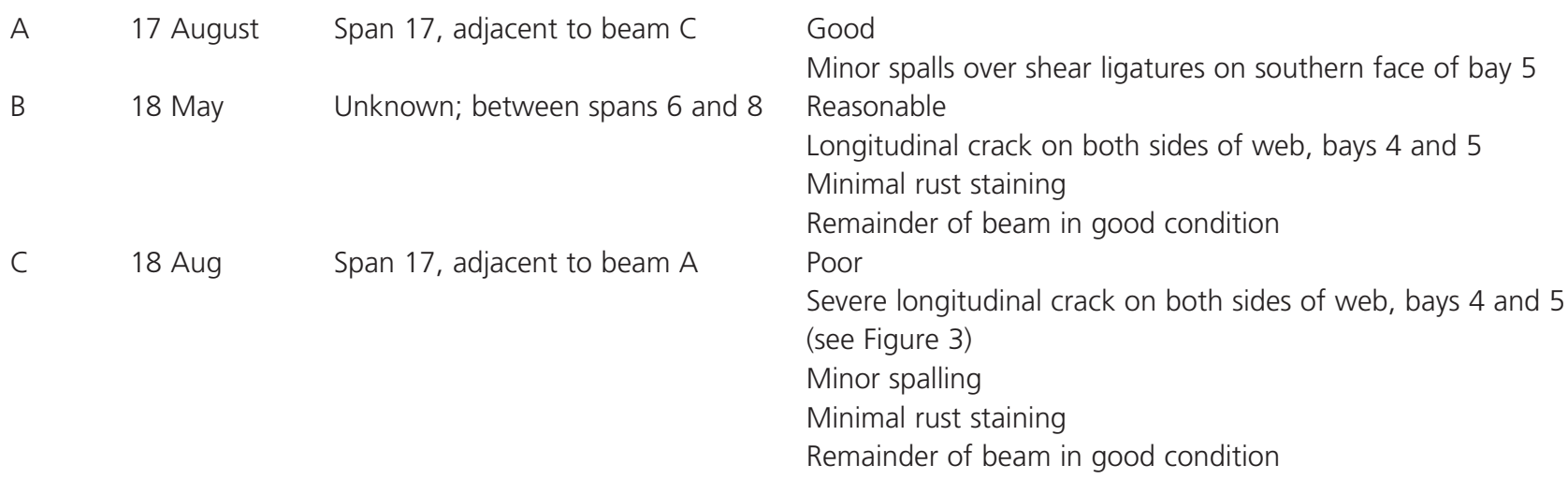

Table 2. Overview of beams selected for current investigation

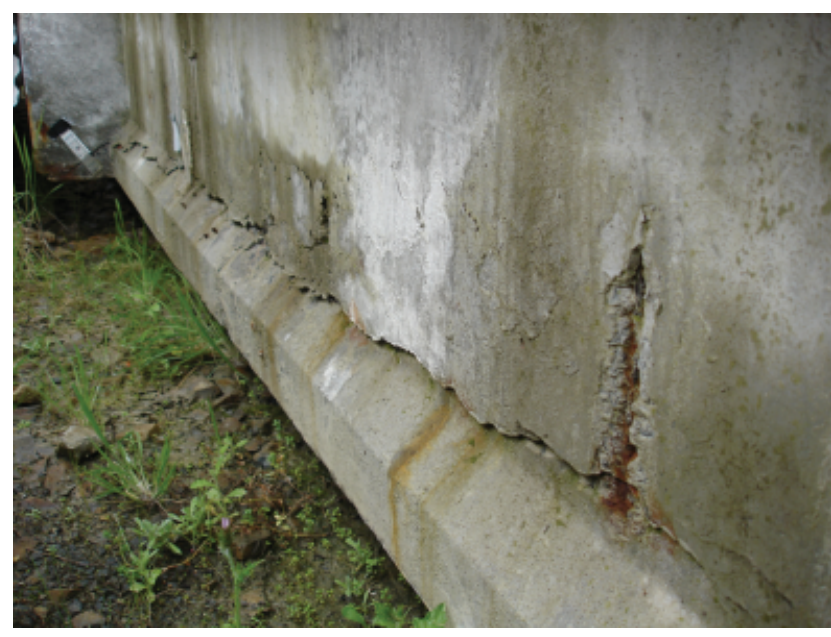

Figure 3. Severe cracking following the lower tendon trajectory in bay 5 of beam $C$, recovered soon after the bridge demolition increment, photographs of crack patterns and of the failure zones were taken once the system achieved a semi-steady state.

\section{Test results}

The load-deflection plots obtained during each load test are shown in Figure 8. The corresponding midspan strain measurements as a function of time over which the tests were conducted are shown in Figure 9. Note that because the failure region in beams $\mathrm{B}$ and $\mathrm{C}$ did not occur at midspan, strains at the failure zone were not recorded. The principal results are summarised also in Table 3.

Beam A, in the best condition superficially, was load tested first. As the applied load approached $50 \mathrm{kN}$, a loud 'popping' sound was heard from within the beam. Increased loading resulted in more such sound events. Each event was found to correspond to a small but distinct peak in the load-deflection plot (Figure 8),
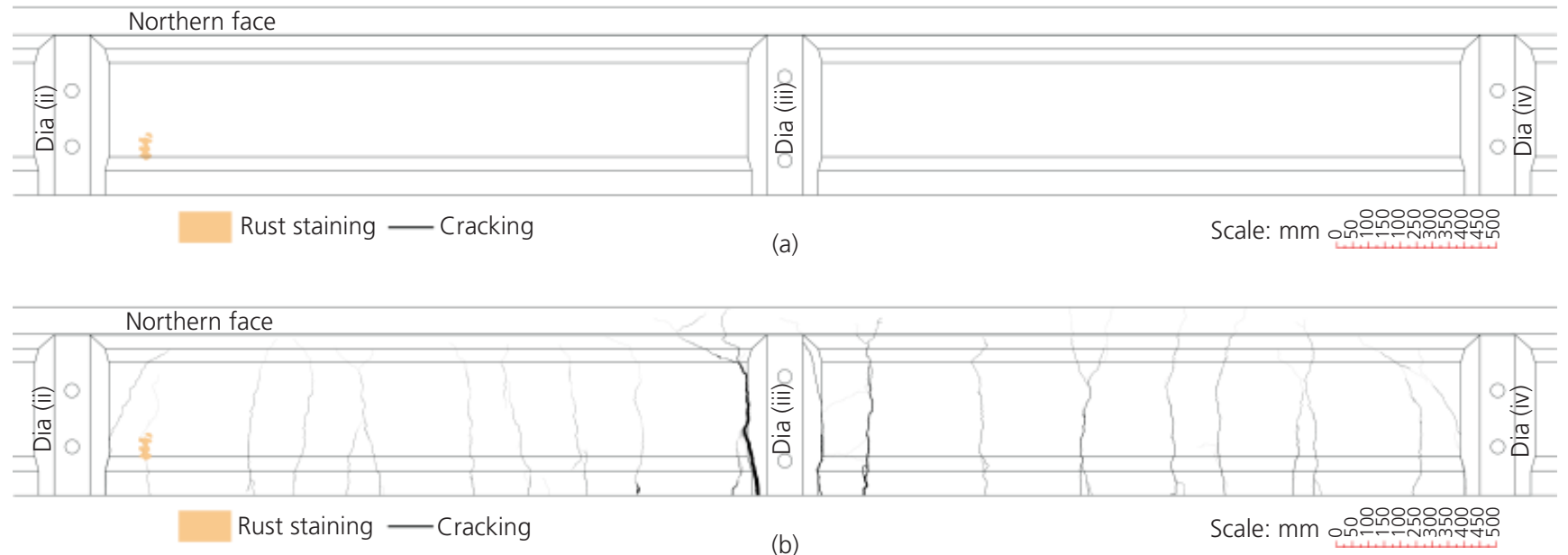

Figure 4. Bays 3 and 4 (northern face) taken (a) before and (b) after load testing of beam $A$ 


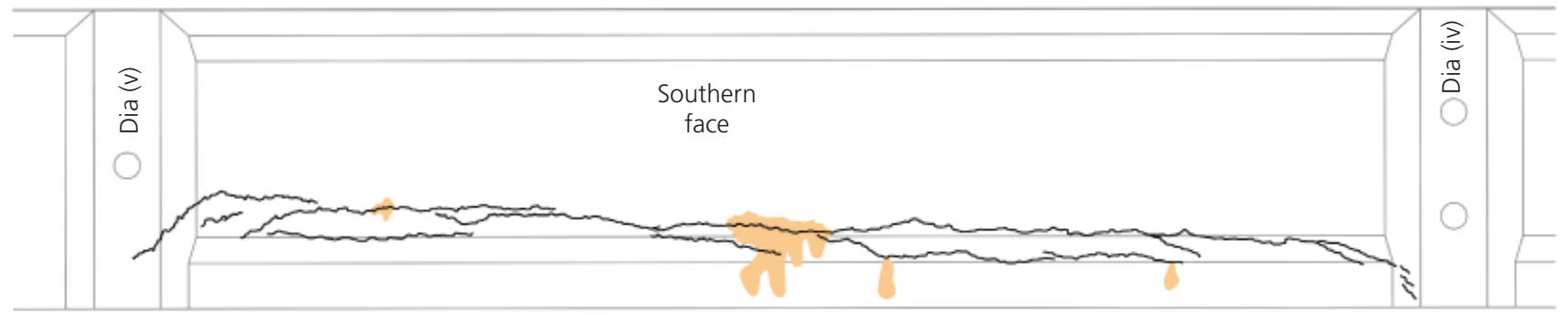

Rust staining _ Cracking

(a)

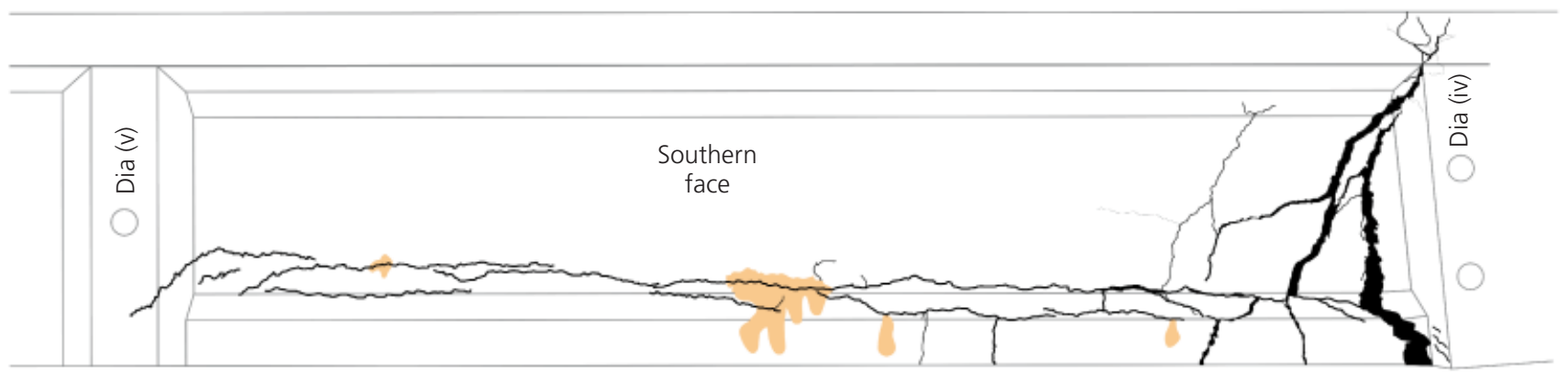

Rust staining C Cracking

(b)

Figure 5. Bay 5 (southern face) (a) before and (b) after load

testing of beam $B$

followed by a small reduction in beam stiffness under the subsequent load increment. A set of jumps in the strain measurement plots was also observed (Figure 9). Approximately ten such events occurred before the ultimate moment of $483 \mathrm{kN} \mathrm{m}$ was reached. The reason behind these events became clear during the autopsy of the beam failure site after testing, which revealed that ten wires had fractured in this location, all of which were in good condition (Figure 10). Figure 4(b) shows that the beam failure occurred in bending at mid-span. The equally spaced cracks in this region are consistent with flexural failure.

Beam B was tested in a similar manner to beam A, with the same sound events noted to commence at approximately $55 \mathrm{kN}$ of applied load. The beam achieved a considerably lower ultimate load, corresponding to an ultimate moment of $333 \mathrm{kN} \mathrm{m}$ (Figure 8). The beam failed in the region adjacent to diaphragm (iv) in bay 5 , with the formation of large diagonal cracks (see Figure 5(b)). Figure 8 shows that the beam failed in a brittle manner, with a very rapid drop-off in capacity after the ultimate moment was reached. The subsequent autopsy of this beam revealed that 17 wires out of a total of 36 had fractured at the failure zone, with the majority of wires showing evidence of corrosion.
Testing of beam $\mathrm{C}$ proceeded in a similar manner to the other two beams; however, its performance was significantly reduced, achieving an ultimate moment of only $243 \mathrm{kN} \mathrm{m}$. As with the other two beams, the sound of fracturing wires commenced at approximately $50 \mathrm{kN}$; however, such events were much more frequent. Not long after the ultimate moment was reached, the beam collapsed suddenly in the region adjacent to diaphragm (iv) in bay 5 (Figure 6(b)). Large diagonal cracks that connected with the original longitudinal web cracking were formed, exposing the prestressing wires from the lower duct (Figure 11). It is clear from Figure 8 that the beam failure was brittle and that there was little reserve ductility once the ultimate moment was reached. Exposure of the failure site revealed that all but three wires of a total of $36 \mathrm{had}$ fractured at the failure location. The shape of the fractured ends of the wires suggests that failure was predominantly brittle. Also, severe corrosion was evident on the majority of wires from this region (Figure 13).

\section{Additional observations}

After the beams were load tested, selected sections were cut into segments for detailed examination. The compressive strength of the concrete was ascertained by retrieving cores (each $95 \mathrm{~mm}$ in diameter) at various locations. Samples of wires were recovered 


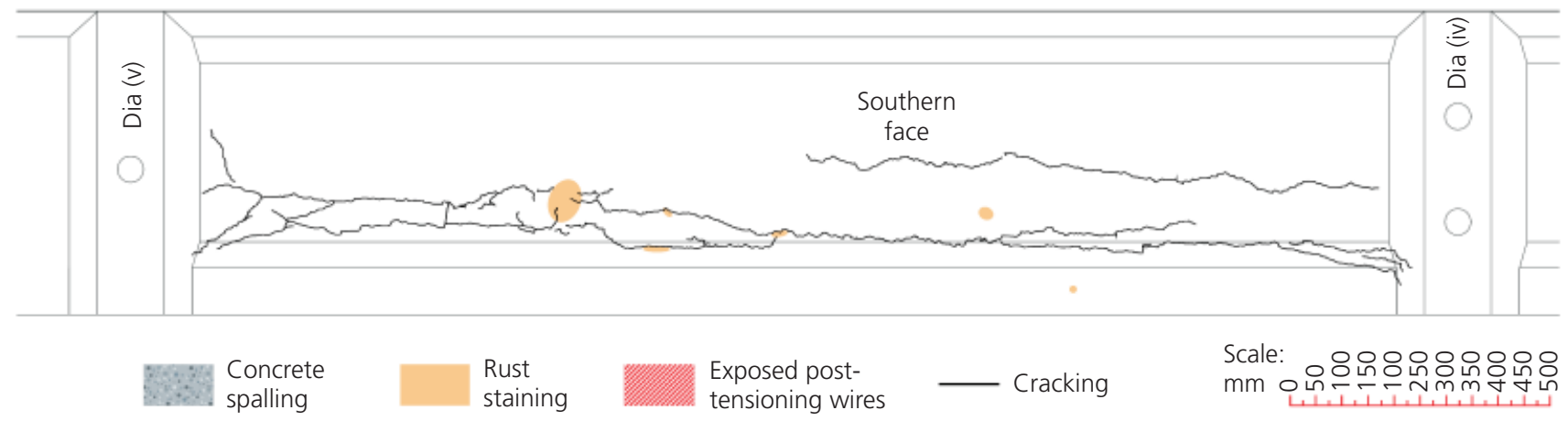

(a)

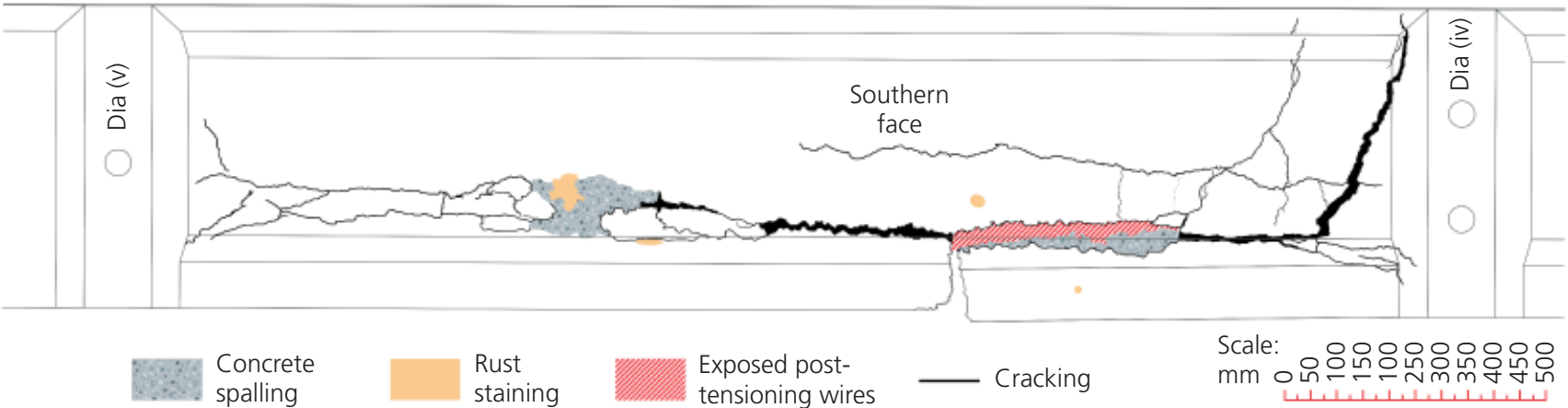

(b)

Figure 6. Bay 5 (southern face) (a) before and (b) after load testing of beam $C$

from the failure zones of each beam, and both wires free of corrosion and some with corrosion were tested for tensile properties. Results from these tests are shown in Table 4. It is evident that both the 5 percentile and mean strengths were equivalent to or exceeded the design specified strengths.

Visual inspections showed that more than $90 \%$ of all prestressing ducts observed were fully grouted. Only minor voids were observed between wires, mainly in isolated areas of upper interfaces of the ducts (see Figure 12). The majority of such voids were observed towards the ends of the beams, and were more prevalent in beam B. Wires located within these voids were mostly in good condition with little or no corrosion, with the exception of those retrieved from bay 5 from beams B and C. Cross-sectional area losses recorded on wires at the failure sites for the upper and lower tendons from beams B and C were $41 \%$ and $73 \%$, and $48 \%$ and $80 \%$ respectively (see Figure 13 ).

Wires at the failure site from beam A (midspan) were in good condition with no significant corrosion. In contrast, significant corrosion losses were recorded on wires from isolated areas in the lower duct of bay 5. Some losses coincided with instances of spalling and rust staining, others offered no visual external evidence. Average cross-sectional area losses in bay 5 were $9 \%$ and $15 \%$ from the upper and lower ducts respectively.

\section{Discussion}

Subsequent to the beams being tested, the ultimate capacity estimates were each updated using the 5 percentile concrete and prestressing wire strengths obtained from materials testing (Table 4). Table 5 shows the theoretical design capacity expected (for a beam in sound condition), the ultimate moments reached in the load tests and the relative percentage. Beam A performed relatively better than beams B and C, but reached only $89 \%$ of the theoretical design capacity. This is in contrast to what normally is expected for actual structures, as the material properties usually provide improved strength characteristics and as such are used in design computations, as indeed is seen in comparing the nominal values in Section 4 with those in Table 4. Beams B and C reached only $61 \%$ and $45 \%$ respectively of the theoretical design capacity.

The lower than expected ultimate capacity of beam A and the much lower ultimate capacities of the other two beams could be the result of one or more factors. First, the geometric configuration of the tendons in response to applied loads may have resulted 


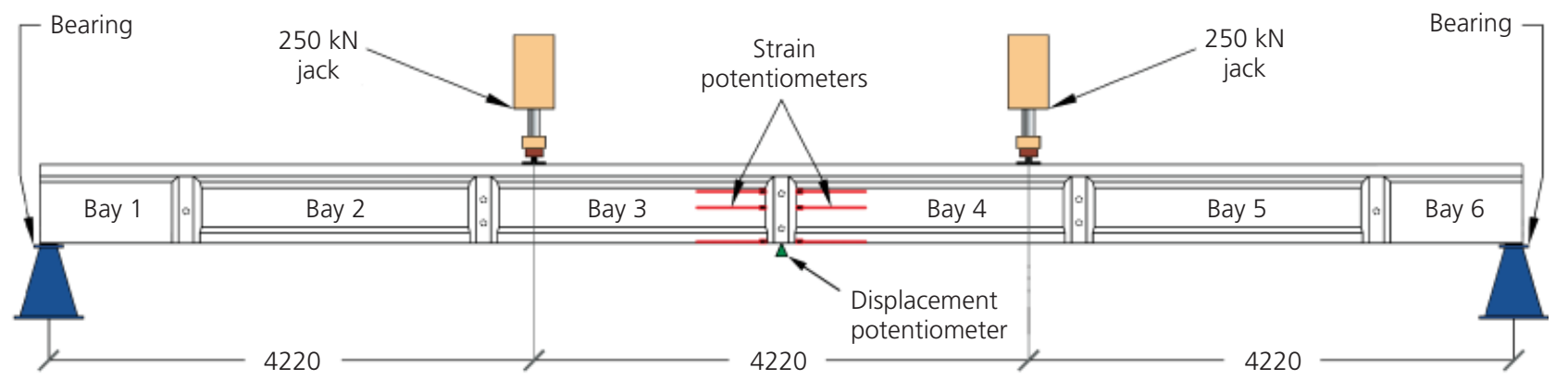

(a)

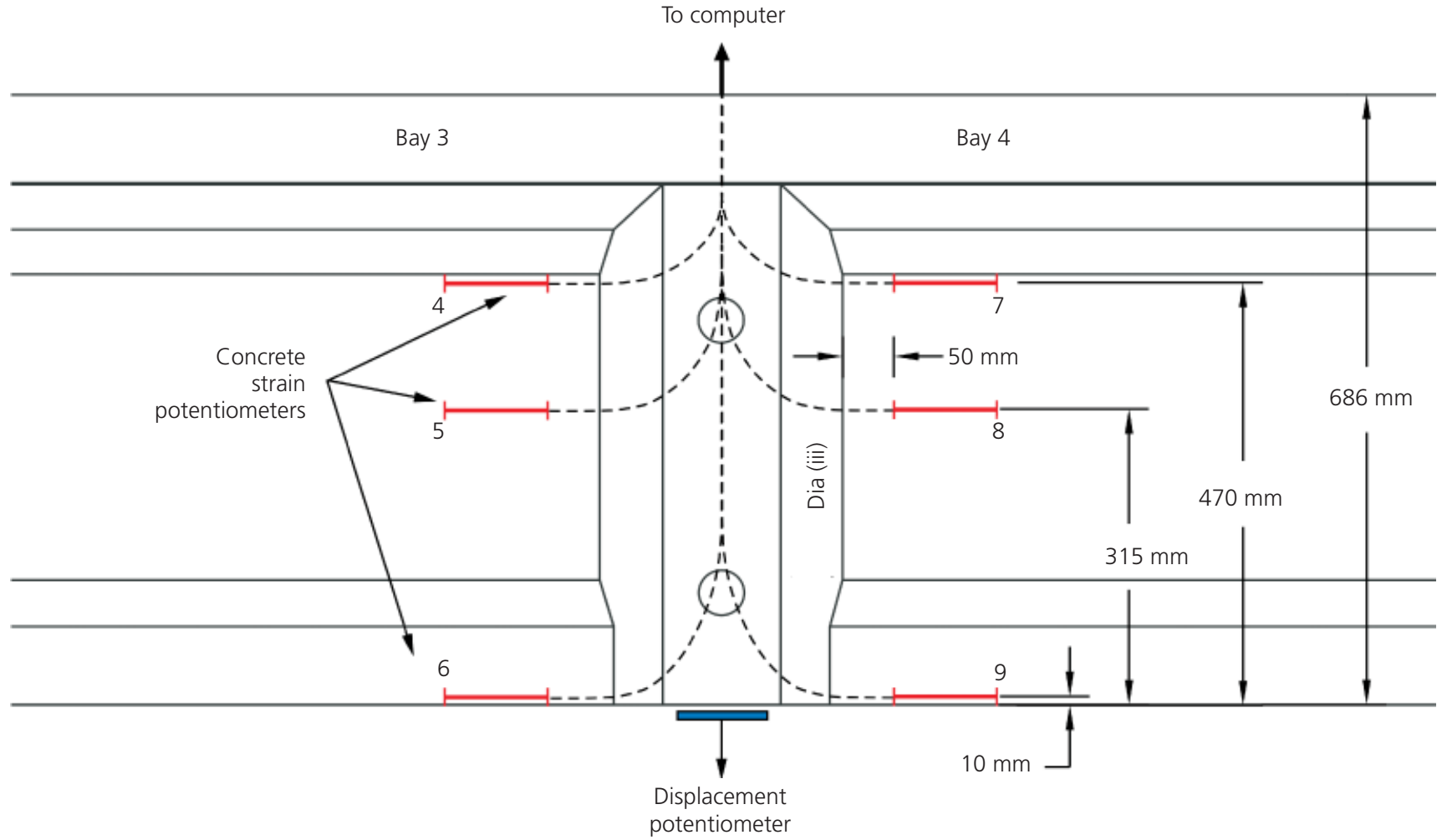

(b)

Figure 7. Load test rig for each beam: (a) overall set-up; (b) the location of strain and displacement potentiometers at midspan

in a reduction in performance; however, it is anticipated that resulting prestress losses would be no greater than $2 \%$. Alternatively, time-dependent prestress losses may have exceeded the $25 \%$ assumed in the estimation of the design capacity of the beams. Others have estimated prestress losses in the range 30 $40 \%$ for existing structures of approximately similar age to the beams considered here (Buchner and Lindsell, 1987; Halsey and Miller, 1996).

A second possibility is the influence of corrosion on the capacity of the prestress wires (Pape and Melchers, 2007). Corrosion of the prestressing wires was severe in beams $\mathrm{B}$ and $\mathrm{C}$ at the failure site within bay 5 , with cross-sectional area losses averaging $60 \%$ (section 6, Figure 13). It can be said that some degree of correlation appears to exist between steel cross-sectional area losses and the ultimate moment achieved (Table 5). This is consistent with observations by others who found also that higher reductions in flexural strength tend to be associated with brittle failure (Malumbela et al., 2010; Rodriguez et al., 1997). For beam $\mathrm{A}$, corrosion was also identified within bay 5 , with crosssectional area losses at the worst location averaging $12 \%$. However, this was not located at the point of failure, and wires within the midspan failure zone were in good condition with no corrosion evident. Therefore, corrosion cannot ultimately be considered responsible for the reduction in capacity for beam A.

The third possibility is that the beams failed in progressive collapse. Such a failure mode would be consistent with the 


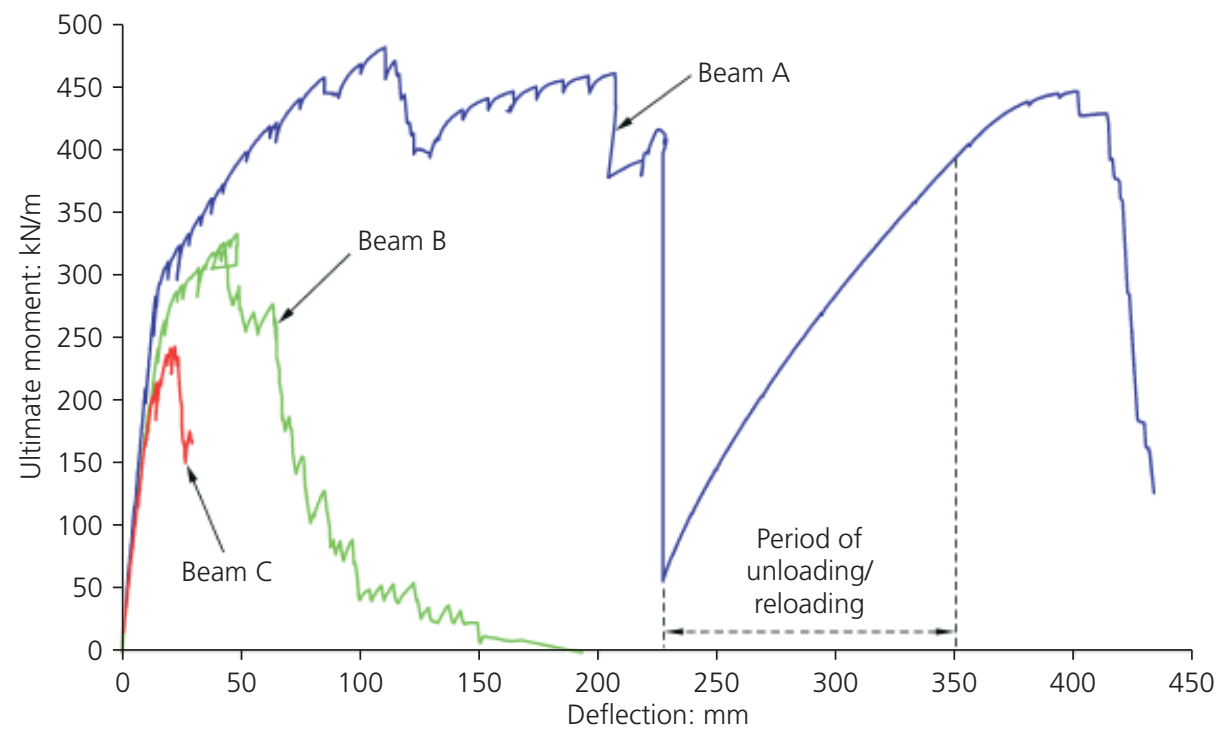

Figure 8. Moment-deflection plots for beams A, B and C. Note that the testing programme for beam $A$ extended over a period of 2 days, with the test intermission shown as 'Period of unloading and reloading'

sounds heard during the load tests, the oscillations in the moment-deflection plots (Figure 8) and the jumps in the strain measurements (Figure 9). Together these suggest that the noises were of wires failing progressively, with associated slight loss of beam stiffness and a jump in strains. Progressive collapse has been proposed as a failure mechanism for badly deteriorated beams (Darmawan and Stewart, 2007), but it does not appear to have been considered for prestressed beams without deterioration. For example, design guides suggest that the ultimate moment capacity of prestressed concrete beams can be based on the entire area of the tensile prestressing steel wires operating in unison and that this remains valid throughout the design life of the structure (Gilbert and Mickleborough, 1990). This implies that the wires can be expected to fail essentially simultaneously once the ultimate capacity is reached. However, this clearly was not the case for beam $\mathrm{A}$.

Other possible reasons for the progressive collapse of beam A could be

(a) stress corrosion cracking (SCC) and hydrogen embrittlement (HE)

(b) fretting fatigue

(c) the influence of aggressive chloride attack.

Stress corrosion cracking is a less commonly known form of corrosion relevant for high-strength steels such as prestressing wires. It is a highly localised form of corrosion with little obvious rust product. It may occur along the wire direction, that is along the elongated grain boundaries, or, less commonly, transversely. This has been attributed to the presence of chlorides in conjunc- tion with the application of high tensile stresses (ACI, 2001). In addition, several cases of brittle failure of prestressed concrete structures have been attributed to SCC (Leonhardt, 1964). HE has been implicated as a potential failure mechanism of cold-drawn prestressing steel (Toribio and Lancha, 1993), but doubt remains whether it is significant with realistic concrete $\mathrm{pH}$ values (Cherry and Price, 1980).

Direct evidence of SCC and HE is difficult to obtain, and in any case was not sought for the beams considered herein. However, there were some direct visual observations which can be considered as consistent with SCC or HE. The failure surfaces of the prestressing wires in beam $\mathrm{C}$ show brittle failure and also some ductility (Figure 14). Close examination showed, however, that one wire had fractured along the length of the wire (inset, Figure 14). This is very unusual for steel stressed in tension, but is similar to the usual failure mode for steel subject to SCC or HE (Ramadan et al., 2008). Similar longitudinal cracks were found in wires in beam B. However, the wires in beam A did not show longitudinal cracking at the failure site.

A further, but seldom described, possibility for progressive failure of the prestressing wires is fretting fatigue (FF). It is usually considered to occur as a result of repeated relative motion between two surfaces in contact (ACI, 2001). Post-tensioned structures are known to be especially at risk owing to the curvature of the tendons and the high radial pressures exerted from the application of the prestress force, in particular where local debonding has occurred (Perrin et al., 2010). Also, FF may arise from contact between a tendon and adjacent localised cracking (Wollmann et al., 1996). A slightly different mechanism 

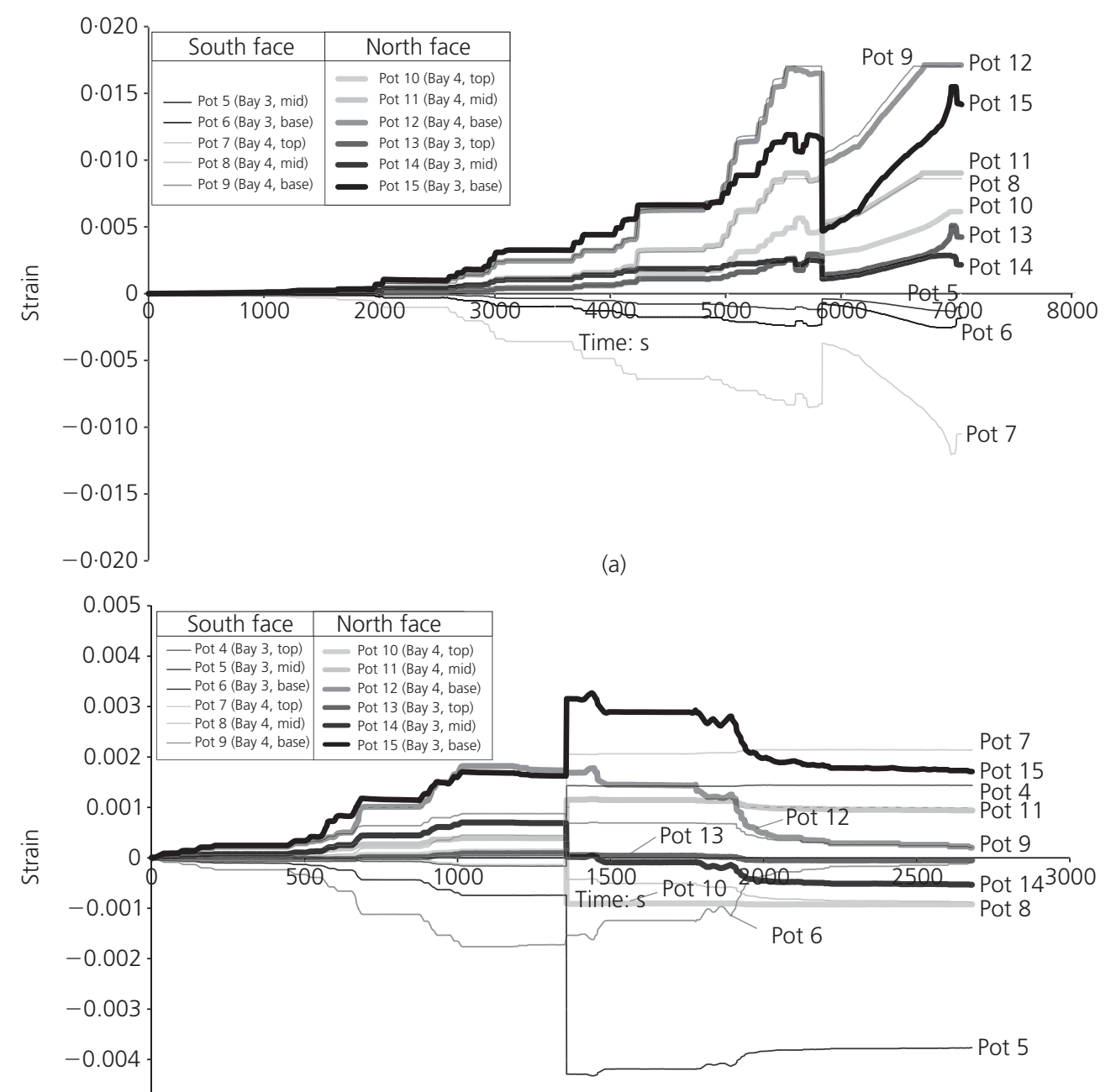

$-0.005$

(b)

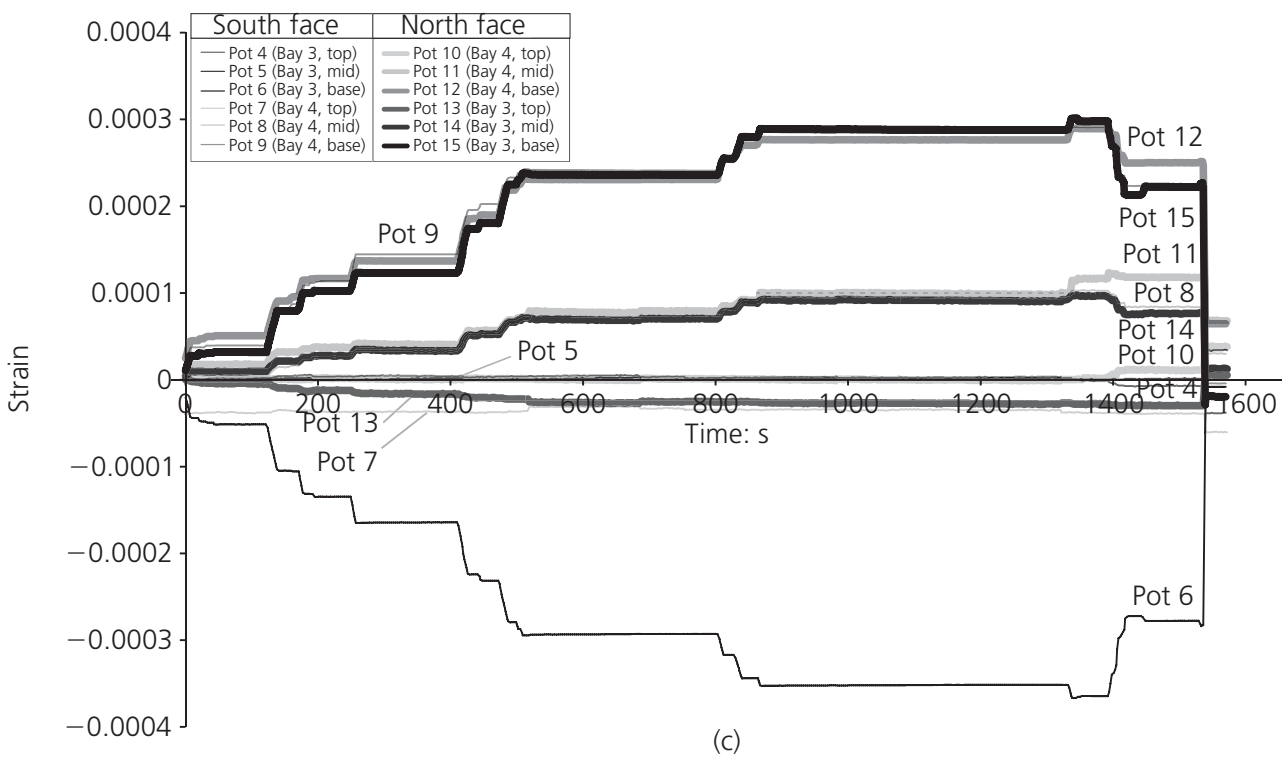

Figure 9. Plots of midspan concrete strains measured continuously during load testing of each beam: (a) beam $A$; (b) beam B; (c) beam C 


\begin{tabular}{llll}
\hline Beam number & Beam A & Beam B & Beam C \\
\hline Ultimate point load: kN & 112 & 77 & 57 \\
Equivalent ultimate moment: kN m & 483 & 333 & 243 \\
Mode and type of failure & Flexure (ductile) & Shear (brittle) & Shear (brittle) \\
Number of fractured wires during test & 10 & 17 & 33 \\
Location of failure (for diaphragm positions, see Figure 2) & Diaphragm (iii) (midspan) & Diaphragm (iv) & Diaphragm (iv) \\
Deflection at ultimate load: mm & 433 & 271 & 102
\end{tabular}

Table 3. Summary of load test results for beams A, B and C
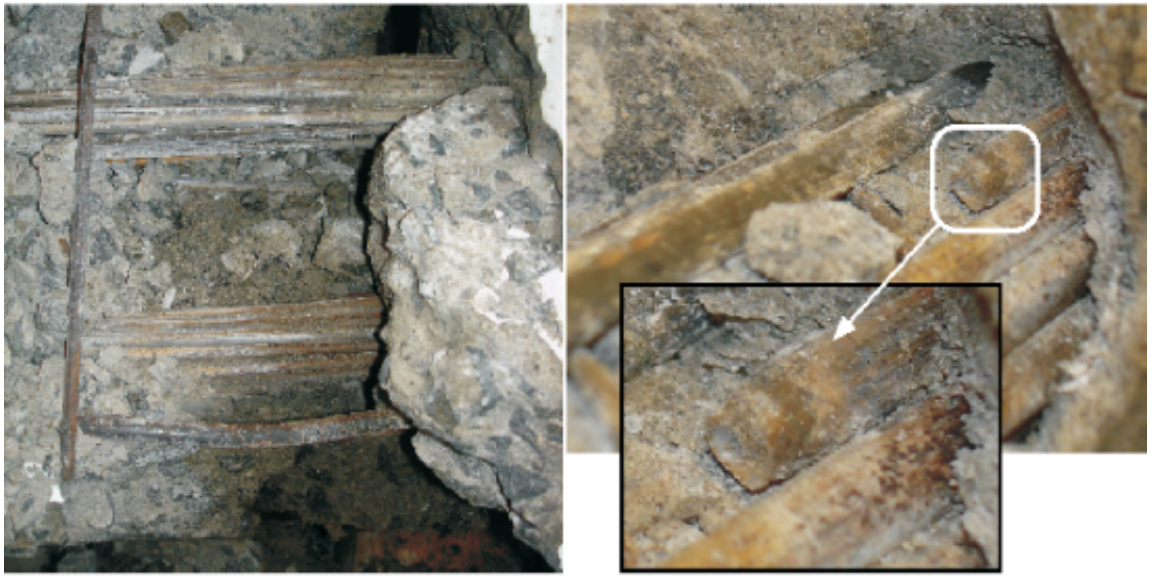

Figure 10. Failure region near diaphragm (iii) of beam A,

showing the prestressing wires, evidence of ductile behaviour prior to fracture and the fractured ends of some of the wires.

None of the wires showed signs of corrosion

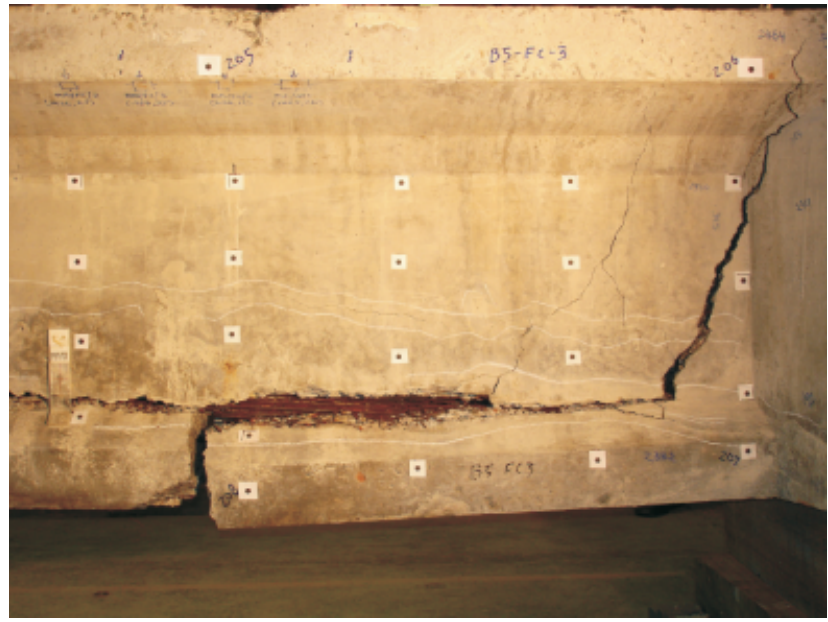

Figure 11. Failure region adjacent to diaphragm (iv) in bay 5 of beam $C$, showing severe local cracking and exposure of the corroded prestressing wires is fretting corrosion (FC), which may occur when oxygen or air as well as water are present at the fatigue location. In the case of the beams considered herein, minor voids were observed along the tops of the ducts (Figure 12) and these could have allowed the prestressing wires to slip against the unlined duct within the void or against each other. In both cases, the driving action for fretting would be the cyclic loading on the bridge beams caused by road traffic. While this scenario is possible, theoretically, visual examination of the wires retrieved from the beams did not reveal abrasion of the wire, as would be expected for FF.

Since the bridge was located in an aggressive marine environment and calcium chloride was added to the beams (although not, as best as could be determined, to the grout in the tendons), it is likely that chlorides caused the aggressive corrosion observed in for beams $\mathrm{B}$ and $\mathrm{C}$ (e.g. Figure 13). For beam A, corroded wires were found only in bay 5 , despite limited external visual evidence. Interestingly, a similar lack of external evidence of internal corrosion on older concrete structures has been described more recently (Melchers et al., 2009). It is completely different to conventional 


\section{Ultimate tensile strength}

\section{Mean strength: $\mathrm{MPa}$}

1870

Maximum strength: $\mathrm{MPa}$

Minimum strength (uncorroded wire): $\mathrm{MPa}$

1800

Minimum strength (corroded wire): $\mathrm{MPa}$

1576

Standard deviation (uncorroded wire): $\mathrm{MPa}$

Number of samples

22

5 percentile strength (uncorroded wire): MPa

Design specification: MPa

1805

1670

\section{Compressive strength}

Mean compressive strength: $\mathrm{MPa}$

Maximum compressive strength: $\mathrm{MPa}$

Minimum compressive strength: $\mathrm{MPa}$

Standard deviation: $\mathrm{MPa}$

Number of samples: MPa

5 percentile compressive strength: $\mathrm{MPa}$

Design specification (28-day compressive

34

strength): $\mathrm{MPa}$

Table 4. Summary of material properties test results

corrosion of steel caused by oxygen, which produces large volumes of red-brown corrosion products such as typically seen at cracks in the concrete parallel to the corroded steel. The corrosion of the wires in beam A could be the result of the aggressiveness of chloride ions in low-oxygen environments (Melchers, 2010). A similar mechanism may explain the aggressive corrosion of the wires in beams $\mathrm{B}$ and $\mathrm{C}$, for which little or no external rust staining was evident despite severely corroded prestressing wires.

The practical implication of the findings reported herein should be of considerable concern. They show that older prestressed concrete beams, with generally good construction and of sound materials, showing no external evidence of deterioration and thus sound, may have some level of deterioration sufficient to cause progressive collapse under load and a reduced ultimate capacity. Given the potentially serious nature of this type of failure mechanism, it is clear that further research is required to improve current understanding of the modes and mechanisms of failure. Such studies can be beneficial in the development of more accurate assessment techniques and predictive tools for life-cycle engineering.

\section{Conclusion}

- The present investigation showed that there may be significant loss of load capacity in prestressed concrete beams with corrosion damage exposed to long-term marine environments

- The load to commencement of progressive collapse, the maximum capacity and the deformation capacity at ultimate capacity were all reduced, approximately linearly, as the degree of corrosion loss in the tendons increased

- Examination of the test results for the beams reported herein shows that the possibility of progressive collapse should be considered for older prestressed concrete beams, particularly when exposed to aggressive marine environments.

- The test results showed that the predicted ultimate capacity of prestressed concrete beams based on current design theory, actual material properties, and free of cracking and corrosion damage may overestimate the actual capacity of the beams.

- These findings are considered to have significant implications for the assessment of the remaining viability of existing prestressed concrete bridges exposed to marine environments.

\section{Acknowledgement}

The work reported herein forms part of a Linkage project supported financially by the Australian Research Council. In addition, the Department of Infrastructure, Energy and Resources has provided financial and in-kind support. Both sources are gratefully acknowledged.
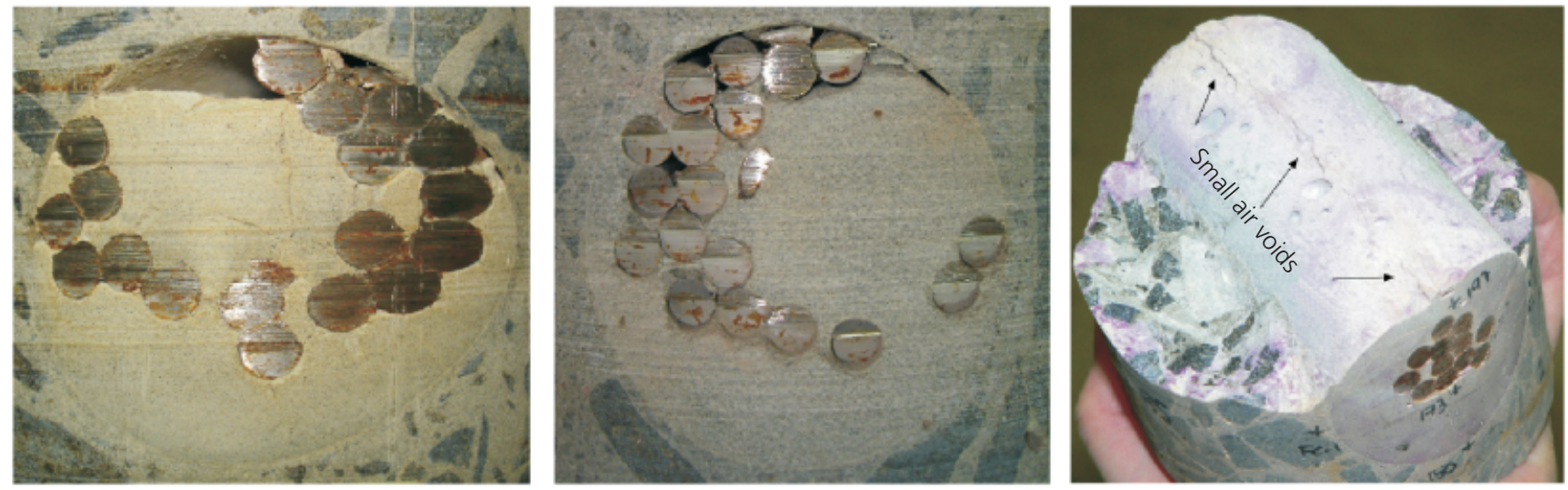

Figure 12. Examples of grout voids for typical cross-sections in the lower tendon grout 


\begin{tabular}{lcrc}
\hline & Beam A & Beam B & Beam C \\
\hline Theoretical design capacity (point load): kN & 126 & 126 & 126 \\
Ultimate point load: kN & 112 & 77 & 57 \\
Equivalent ultimate moment: kN m & 483 & 333 & 243 \\
Failure location (for positions of diaphragms, see Figure 2) & Diaphragm (iii) (midspan) & Diaphragm (iv) & Diaphragm (iv) \\
Percentage of theoretical design capacity & $89 \%$ & $61 \%$ & $45 \%$ \\
Percentage of beam A & $100 \%$ & $69 \%$ & $51 \%$ \\
Maximum loss of prestressing cross-sectional area due to & $0 \%$ & $57 \%$ & $64 \%$
\end{tabular}
corrosion at failure location (upper + lower tendons)
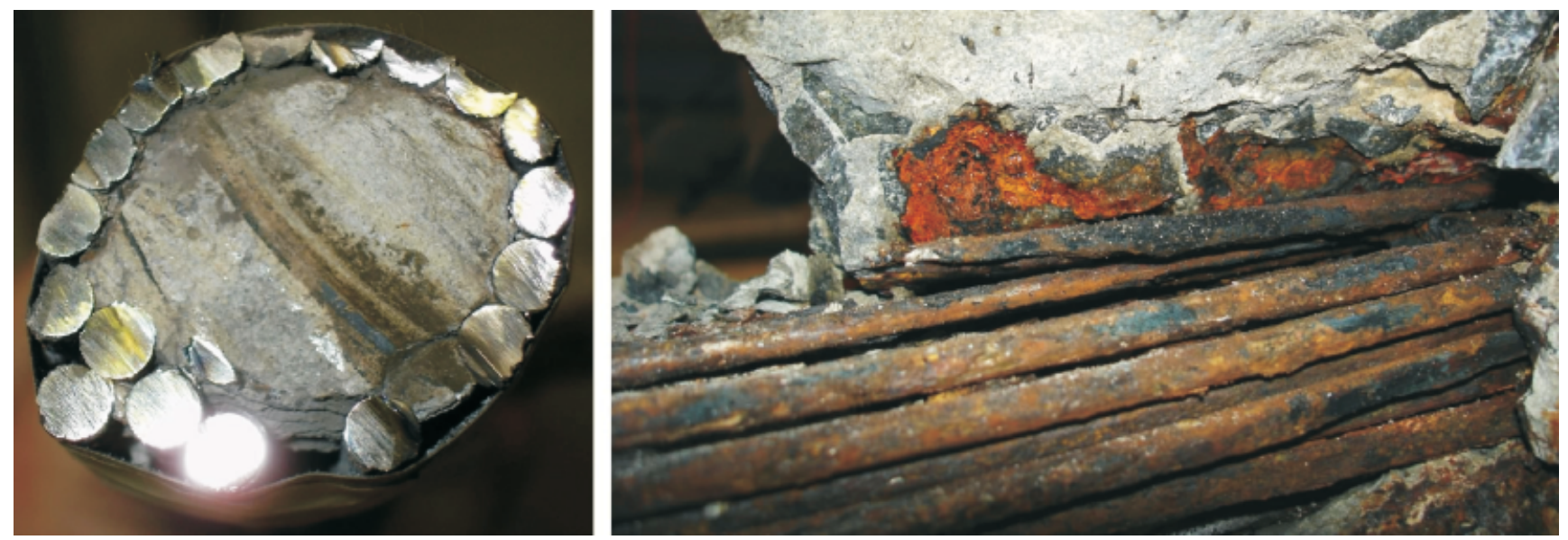

Figure 13. Severe corrosion and minimal rust staining on prestressing wires from failure location in beam $\mathrm{C}$

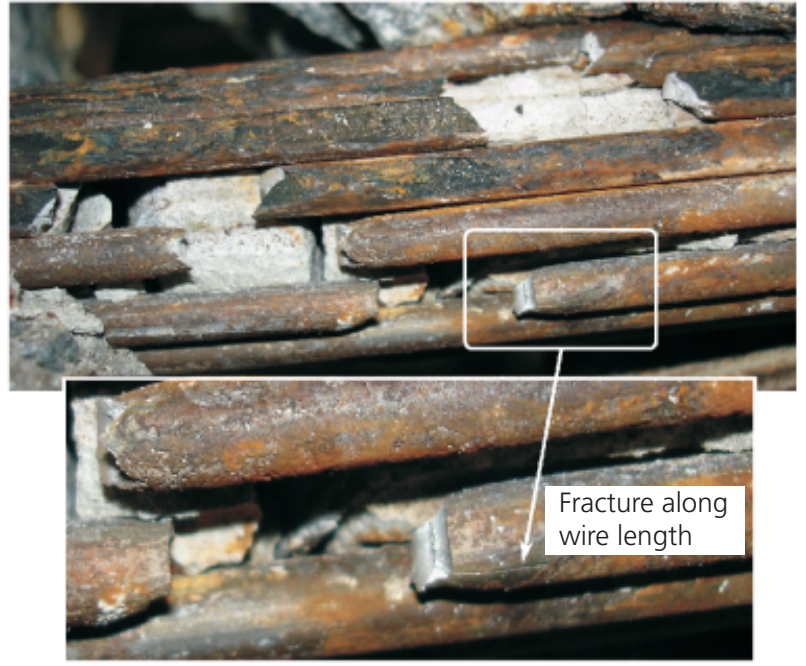

Figure 14. Brittle fracture of prestressing wire at the lower duct failure location in beam $C$

\section{REFERENCES}

Abeles P and Bardhan-Roy B (1981) Prestressed Concrete Designer's Handbook. Cement and Concrete Association, Wexham Springs, Slough, UK.

ACI (American Concrete Institute) (2001) Corrosion of Prestressing Steels. American Concrete Institute, Farmington Hills, MI, USA, ACI222.2R-01.

Buchner S and Lindsell P (1987) Testing of prestressed concrete structures during demolition. Proceedings of the 1st IStructE/ BRE International Seminar on Structural Assessment - Based on Full and Large Scale Testing. Butterworths, Watford, UK, pp. 46-54.

Cairns J, Plizzari GA, Du Y, Law DW and Franzoni C (2005) Mechanical properties of corrosion-damaged reinforcement. ACI Materials Journal 102(4): 256-264.

Cavell DG and Waldron P (2001) A residual strength model for deteriorating post-tensioned concrete bridges. Computers and Structures 79(4): 361-373.

Cherry BW and Price SM (1980) Pitting, crevice and stress corrosion cracking studies of cold drawn eutectoid steels. Corrosion Science 20(11-12): 1163-1184. 
Coombs W (1957) The Sorell Causeway Bridge: Longest prestressed concrete bridge in Australia. Tasmanian Architect, June: pp. 24-25.

Coronelli D, Castel A, Vu NA and François R (2009) Corroded post-tensioned beams with bonded tendons and wire failure. Engineering Structures 31(8): 1687-1697.

Darmawan MS and Stewart MG (2007) Spatial time-dependent reliability analysis of corroding pretensioned prestressed concrete bridge girders. Structural Safety 29(1): 16-31.

Gilbert R and Mickleborough N (1990) Design of Prestressed Concrete. Unwin Hyman, London, UK.

Halsey JT and Miller R (1996) Destructive testing of two fortyyear-old prestressed concrete bridge beams. PCI Journal 41(5): 84-93.

LeBeau K and Wadia-Fascetti S (2010) Predictive and diagnostic load rating model of a prestressed concrete bridge. Journal of Bridge Engineering 15(4): 399-407.

Leonhardt F (1964) Prestressed Concrete Design and Construction. Wilhelm Ernst and Sons, Berlin, Germany.

Malumbela G, Alexander M and Moyo P (2010) Variation of steel loss and its effect on the ultimate flexural capacity of $\mathrm{RC}$ beams corroded and repaired under load. Construction and Building Materials 24(6): 1051-1059.

Melchers R (2010) Carbonates, carbonation and the durability of reinforced concrete marine structures. Australian Journal of Structural Engineering 10(3): 215-226.

Melchers R, Li C and Davidson M (2009) Observations and analysis of a 63-year old reinforced concrete promenade railing exposed to the North Sea. Magazine of Concrete Research 61(4): 233-243.

Neves LC and Frangopol D (2008) Life-cycle performance of structures: combining expert judgment and results of inspection. In Proceedings of the 1st International Symposium on Life-Cycle Civil Engineering (Biondini F and Frangopol D (eds)). CRC Press, Boca Raton, FL, USA, pp. 409-414.

Pape TM and Melchers RE (2007) The effect of corrosion on 45 year-old prestressed concrete bridge beams. Proceedings of the Corrosion and Prevention Conference, Sydney, Australia, 25-28 November.

Pape TM and Melchers RE (2011) The effects of corrosion on 45year-old pre-stressed concrete bridge beams. Structure and Infrastructure Engineering 7(1-2): 101-108.

Perrin M, Gaillet L, Tessier C and Idrissi H (2010) Hydrogen embrittlement of prestressing cables. Corrosion Science 52(6): 1915-1926.

Ramadan S, Gaillet L, Tessier C and Idrissi H (2008) Assessment of the stress corrosion cracking in a chloride medium of cables used in prestressed concrete structures by the acoustic emission technique. Measurement Science and Technology 19(11): 115702.1-115702.9.

Rodriguez J, Ortega L and Casal J (1997) Load carrying capacity of concrete structures with corroded reinforcement. Construction and Building Materials 11(4): 239-248.

Schupack M (1978) A survey of the durability performance of post-tensioning tendons. ACI Journal 75(10): 501-510.
Standards Australia (2004) AS5100.7: Bridge design - Part 7: Rating of existing bridges. Standards Australia, Sydney, Australia.

Ting S and Nowak AS (1991) Effect of tendon-area loss on flexural behavior of $\mathrm{P} / \mathrm{C}$ beams. Journal of Structural Engineering 117(4): 1127-1143.

Toribio J and Lancha A (1993) Effect of cold drawing on susceptibility to hydrogen embrittlement of prestressing steel. Materials and Structures 26(1): 30-37.

Val D and Chernin L (2008) Service-life performance of reinforced concrete structures in corrosive environments. In Proceedings of the 1st International Symposium on Life-Cycle Civil Engineering (Biondini F and Frangopol D (eds)). CRC Press, Boca Raton, FL, USA, pp. 247-252.

Wollmann GP, Yates DL, Breen JE and Kreger ME (1996) Fretting fatigue in post-tensioned concrete beams. ACI Structural Journal 93(2): 172-179.

Woodward R and Williams R (1988) Collapse of Ynys-y-Gwas Bridge, West Glamorgan. Proceedings of the Institution of Civil Engineers - Design and Construction 84(August): 635-669.

Zeng YH, Huang QH, Gu XL and Zhang WP (2010) Experimental study on bending behavior of corroded post-tensioned concrete beams. In Proceedings of the 12th International Conference on Earth and Space 2010: Engineering, Science, Construction, and Operations in Challenging Environments (Song G and Malla RB (eds)). American Society of Civil Engineers (ASCE), Reston, VI, USA, vol. 366, pp. $3521-$ 3528.

Zollman CC, Depman F, Nagle J and Hollander EF (1992) Building and rebuilding of Philadelphia's Walnut Lane Memorial Bridge - Part 1: A history of design, construction and service life. PCI Journal 37(3): 66-82.

\section{WHAT DO YOU THINK?}

To discuss this paper, please email up to 500 words to the editor at journals@ice.org.uk. Your contribution will be forwarded to the author(s) for a reply and, if considered appropriate by the editorial panel, will be published as a discussion in a future issue of the journal.

Proceedings journals rely entirely on contributions sent in by civil engineering professionals, academics and students. Papers should be 2000-5000 words long (briefing papers should be 1000-2000 words long), with adequate illustrations and references. You can submit your paper online via www.icevirtuallibrary.com/content/journals, where you will also find detailed author guidelines. 